\title{
QUALIDADE FÍSICA DOS GRÃOS DE SOJA, CULTIVAR TMG115RR, SUBMETIDOS À SIMULAÇÃO DE CHUVA DURANTE O RETARDAMENTO DE COLHEITA
}

\section{PHYSICAL QUALITY OF SOYBEAN GRAINS, CULTIVAR TMG115RR, SUBMITTED TO SIMULATION OF RAIN DURING THE DELAY OF HARVEST}

\author{
Patrícia de Jesus ANDRADE ${ }^{1,2}$ \\ Alessandro FERRONATO ${ }^{3}$ \\ José Holanda CAMPELO JUNIOR ${ }^{4}$ \\ Maria Aparecida Braga CANEPPELE ${ }^{5}$
}

\section{RESUMO}

A ocorrência de chuvas pode diminuir a qualidade dos grãos, pelas suas sucessivas retrações e intumescimentos, à medida que se retarda a colheita. O objetivo deste trabalho foi avaliar a qualidade física dos grãos de soja da cultivar TMG115RR, submetida a quatro tempos de simulação de chuva (testemunha, uma, duas e três horas) e colhidas em estádio R9 e após cinco, 10, 15 e 22 dias para outubro de 2007 e em estádio R9 e após cinco, 10 e 15 para abril de 2008; no campo experimental do Centro Universitário de Várzea Grande/MT. Após a colheita, realizou-se a determinação do teor de água e classificação física com os grãos. Em outubro de 2007, com cinco dias de irrigação o total de grãos avariados excedeu o limite máximo de tolerância previsto na legislação brasileira. Aos 10 dias de retardamento de colheita, a porcentagem de grãos mofados excedeu em quatro vezes o limite máximo de tolerância para comercialização destinada à indústria ou outros fins. Para abril de 2008 a porcentagem de teor de água dos grãos, da segunda colheita, estava superior ao recomendável para a manutenção da qualidade dos mesmos, que é de $14 \%$. O defeito de maior ocorrência nos dois anos foram grãos mofados. A testemunha apresentou porcentagens de grãos avariados superior a $8 \%$. Ao final dos 15 dias de retardamento de colheita, mais de $50 \%$ dos grãos estavam avariados. O retardamento de colheita associado com chuvas de final de colheita provocam a deterioração dos grãos.

Palavras-chave: perdas qualitativas; qualidade comercial; deterioração.

\section{ABSTRACT}

The occurrence of rain can reduce the quality of grain, because of the successive retractions and swelling, as the harvest is delayed. The objective of this research was evaluating physical quality of the soy grains, cultivar TMG115RR, submitted to four times of simulation of rain (control treatment, one, two and three hours) and harvest at stadium R9 and after five, 10, 15 and 22 days in October 2007 and stadium R9 and after five, 10 and 15 for April 2008, in the experimental field at the University of Várzea Grande-MT. In October 2007, with 5 days simulation of rain the total of damaged grains exceeded the limit of tolerance provided in brazilian legislation. At 10 days of harvested retardation the percentage of grains moldy exceeded four times the limit of tolerance for marketing for the industry or other purposes. In cropping seasons of April 2008 the percentage of water content of grain, the second harvest, was higher than recommended for the maintenance of their quality, which is $14 \%$. The defect of higher occurrence in the two years was moldy grains. The control treatment showed percentages of damaged grain more than $8 \%$. At the end of 15 days to delay the harvest, more than $50 \%$ of grains were damaged. The delay of harvest associated with the end of harvest rains cause the deterioration of grain.

Key-words: qualitative losses; commercial quality; deterioration.

\footnotetext{
${ }^{1}$ Estudante de Pós-Graduação do Programa de Agricultura Tropical, Universidade Federal de Mato Grosso, Cuiabá, Mato Grosso, Brasil. Email: patriciajandrade@gmail.com

${ }^{2}$ Av. Cel. Julião de Brito Qd. 43 Lt. 08, Parque do Lago - Várzea Grande/MT - CEP: 78120-400. Autor para correspondência

${ }^{3}$ MSc, estudante de Pós-Graduação do Programa de Agricultura Tropical, Universidade Federal de Mato Grosso, Cuiabá, Mato Grosso, Brasil. E-mail: aleferro@gmail.com

${ }^{4}$ Professor Dro do Programa de Pós Graduação em Agricultura Tropical, Universidade Federal de Mato Grosso, Cuiabá, Mato Grosso, Brasil. E-mail: campelo@cpd.ufmt.br

${ }_{5}^{5}$ Professor Dra. do Departmento de Agronomia, Universidade de Federal de Mato Grosso, Cuiabá, Mato Grosso, Brasil. E-mail: canepele@terra.com.br
} 


\section{INTRODUÇÃO}

Sabe-se que, após a maturação fisiológica, o grão pode ser considerado como armazenado em campo, enquanto a colheita não se processa. Se as condições climáticas forem favoráveis, desde a maturação fisiológica até a época normal de colheita, os problemas de deterioração serão amenizados. Entretanto, se no período de maturação, ocorreram índices elevados de precipitações pluviométricas, flutuações de umidade relativa do ar, variações da temperatura ambiental, resultarão em grandes perdas na qualidade física e sanitária dos grãos.

Os níveis de tolerância à deterioração no campo diferem entre cultivares e entre ambientes, porém as condições meteorológicas como temperatura elevada e precipitação são mais importantes que o tempo de permanência do produto no campo após a maturação fisiológica (Sediyama et al.,1981). Braccini et al. (2003, estudando a qualidade fisiológica e sanitária de 15 cultivares de soja colhidas em diferentes épocas relataram que houve diferença significativa de comportamento entre as cultivares quanto à tolerância ao retardamento da colheita. Silva et al. (1979), avaliando quatro épocas diferentes de colheita das sementes de soja de duas cultivares, verificaram que a época mais favorável para essa operação variou com a cultivar, dependendo do teor de água das sementes por ocasião da colheita.

Estudos realizados por Costa et al. (2003) mostraram que a qualidade dos grãos provenientes de algumas regiões do Brasil tem sido severamente comprometida em função dos elevados índices de deterioração por umidade, lesões por percevejos, por quebras e rupturas do tegumento. Panizzi et al. (1979) observaram que a alta proporção de microorganismos estava associada com sementes danificadas, dentre estes Fusarium sp., infectando mais de $30 \%$ de grãos lesionadas por percevejos.

Em consideração ao relatado acima, sobre a qualidade dos grãos no momento da colheita, este trabalho teve 0 objetivo de acompanhar o desempenho da qualidade física dos grãos de soja, cultivar TMG115RR, no estádio de maturação (R9) e ao longo de 15 dias, submetidas a três tempos de simulação de chuva.

\section{MATERIAL E MÉTODOS}

O experimento foi conduzido no Centro Universitário de Várzea Grande - UNIVAG, Município de Várzea Grande - MT (latitude15 $5^{\circ}$ 38,65' S; longitude 56 05,92' W; altitude $192 \mathrm{~m}$ ). O clima da região de estudo é classificado do tipo Aw conforme a classificação de Köppen, clima com chuva de verão, e o mês mais frio tem temperatura média superior a $18{ }^{\circ} \mathrm{C}$ (Ayoad, 2007). O solo da área experimental foi caracterizado como Latossolo vermelho amarelo distrófico, de textura arenosa/ média e relevo plano. Os grãos de soja foram colhidos em duas épocas diferentes a primeira em outubro de 2007 e a segunda em abril de 2008. A semeadura para o primeiro ano foi realizada no dia $12 / 05 / 2007$ e para o segundo no dia 20/11/2008. O cultivo foi realizado em fileiras com $45 \mathrm{~cm}$ de espaçamento e densidade de 12 plantas por metro linear (267.000 plantas ha $\left.{ }^{-1}\right)$. A emergência de $70 \%$ das plântulas ocorreu no dia 17 de maio, para o primeiro ano e no dia 26 de novembro para o segundo ano. A única operação realizada neste solo foi a abertura manual dos sulcos de semeadura. A adubação de base foi realizada a partir da interpretação da análise de solo. O controle de pragas e doenças, quando necessário, foi realizado com produtos químicos.

A área experimental constituiu-se de duas parcelas de $750 \mathrm{~m}^{2}$, com 67 linhas sendo uma irrigada e a outra não (testemunha). O experimento foi instalado em delineamento inteiramente casualizado em esquema fatorial com quatro épocas de colheita (Testemunha, 5 (primeira colheita), 10 (segunda colheita) e 15 dias (terceira colheita) após R9), e quatro tempos de simulação de chuva (T1 - 1 h de simulação de chuva; T2 - 2 h de simulação de chuva; T3 -3 h de simulação de chuva; T4 - Testemunha, sem simulação de chuva) e cinco repetições. No experimento realizado em outubro de 2007 foi realizada uma quarta colheita aos 22 dias após R9. As parcelas experimentais foram divididas em sub-parcelas de $2 \mathrm{~m}^{2}$ para a instalação dos tratamentos.

Foram colhidas 15 plantas, a cada 5 dias, as duas fileiras centrais, das quatro de cada subparcela. Após a colheita, as vagens foram debulhadas manualmente e retirada $50 \mathrm{~g}$ de grãos para a determinação do teor de água do ponto de colheita.

A simulação de chuva foi efetuada através de um conjunto de nove aspersores instalados em malha quadrada de $6 \times 6 \mathrm{~m}$, de forma a obter homogeneidade na lâmina de água em todos os tratamentos. De acordo com as possibilidades, a simulação de chuva foi realizada entre 6 e $9 \mathrm{~h}$, entretanto, nos dias 14 e 23/04/08 foi realizada entre 14 e $17 \mathrm{~h}$.

No início da simulação de chuva os tratamentos de uma e duas horas foram protegidos por uma lona plástica preta, a qual foi retirada após duas e uma hora, respectivamente, de simulação.

A lâmina de água, para cada uma hora de simulação, foi medida através de oito pluviômetros distribuídos em toda a área experimental. O volume de água resultante da simulação de chuva, encontra-se nas Tabelas 1 e 2, para os períodos de 04 a 25/10/2007 e de 09 a 24/04/2008, respectivamente, para o primeiro e segundo ano do experimento. A testemunha recebeu água através das precipitações ocorridas no período do experimento. 
ANDRADE, P. et al. Qualidade física dos grãos de soja...

TABELA 1 - Valores de volume de água, resultantes da simulação de chuva, e lâmina de água acumulada na época de colheita de soja, no experimento instalado no UNIVAG, Várzea Grande/MT, em outubro de 2007.

\begin{tabular}{|c|c|c|c|c|c|}
\hline \multirow{3}{*}{ Época de Colheita } & \multirow{3}{*}{ Data } & \multicolumn{4}{|c|}{ Lâmina de molhamento } \\
\hline & & 0 hora & $1 \mathrm{~h}$ & $2 \mathrm{~h}$ & $3 \mathrm{~h}$ \\
\hline & & \multicolumn{3}{|c|}{ Volume de água (mm) } & \\
\hline R9** (testemunha) & 01/10/2007 & 0,00 & 0,00 & 0,00 & 0,00 \\
\hline Acumulado & $1^{\circ}$ colheita & 0,00 & 0,00 & 0,00 & 0,00 \\
\hline R9+1 dia & $4 / 10 / 2007$ & 0,00 & 9,65 & 16,18 & 22,06 \\
\hline $\mathrm{R} 9+2$ dias & $5 / 10 / 2007$ & 0,00 & 7,54 & 14,45 & 20,32 \\
\hline $\mathrm{R} 9+3$ dias & $6 / 10 / 2007$ & 0,00 & 3,95 & 11,80 & 20,88 \\
\hline $\mathrm{R} 9+4$ dias & $7 / 10 / 2007$ & 0,00 & 5,70 & 11,93 & 17,81 \\
\hline $\mathrm{R} 9+5$ dias & $8 / 10 / 2007$ & 0,00 & 6,32 & 13,60 & 22,10 \\
\hline Acumulado (5 dias) & $2^{\circ}$ colheita & 0,00 & 33,16 & 67,95 & 103,17 \\
\hline $\mathrm{R} 9+6$ dias & 9/10/2007 & 0,00 & 10,09 & 18,24 & 27,94 \\
\hline $\mathrm{R} 9+7$ dias & $10 / 10 / 2007$ & 0,00 & 6,05 & 12,63 & 19,25 \\
\hline $\mathrm{R} 9+8$ dias & $11 / 10 / 2007$ & 0,00 & 8,46 & 17,59 & 26,14 \\
\hline $\mathrm{R} 9+9$ dias & $12 / 10 / 2007$ & $10,92^{*}$ & 10,92 & 10,92 & 10,92 \\
\hline $\mathrm{R} 9+10$ dias & $13 / 10 / 2007$ & 0,00 & 8,07 & 16,18 & 25,74 \\
\hline Acumulado (10 dias) & $3^{\circ}$ colheita & 10,92 & 76,75 & 143,51 & 213,16 \\
\hline R9+11 dias & $14 / 10 / 2007$ & $2,59^{*}$ & 11,23 & 20,83 & 29,16 \\
\hline $\mathrm{R} 9+12$ dias & $15 / 10 / 2007$ & $56,84^{*}$ & 56,84 & 56,84 & 56,84 \\
\hline $\mathrm{R} 9+13$ dias & $16 / 10 / 2007$ & 0,00 & 9,61 & 18,60 & 27,10 \\
\hline $\mathrm{R} 9+14$ dias & $17 / 10 / 2007$ & 0,00 & 7,41 & 15,26 & 22,15 \\
\hline $\mathrm{R} 9+15$ dias & $18 / 10 / 2007$ & $57,60^{*}$ & 57,60 & 57,60 & 57,60 \\
\hline Acumulado (15 dias) & $4^{\circ}$ colheita & 127,95 & 219,44 & 312,64 & 406,01 \\
\hline $\mathrm{R} 9+22$ dias & $25 / 10 / 2007$ & 14,80 & 14,80 & 14,80 & 14,80 \\
\hline Acumulado (22 dias) & $5^{\circ}$ colheita & 142,75 & 234,24 & 327,44 & 420,80 \\
\hline
\end{tabular}

* Registro de precipitações. ${ }^{*}$ Estádio de desenvolvimento R9 - Ponto de maturação do grão e colheita. 
ANDRADE, P. et al. Qualidade física dos grãos de soja...

TABELA 2 - Valores de volume de água, resultantes da simulação de chuva, e lâmina de água acumulada na época de colheita de soja, no experimento instalado no UNIVAG, Várzea Grande-MT, em abril de 2008.

\begin{tabular}{|c|c|c|c|c|c|}
\hline \multicolumn{6}{|c|}{ Volume de água (mm) } \\
\hline \multirow{2}{*}{ Época } & \multirow{2}{*}{ Data } & \multicolumn{4}{|c|}{ Lâmina de molhamento } \\
\hline & & 0 & $1 \mathrm{~h}$ & $2 \mathrm{~h}$ & $3 \mathrm{~h}$ \\
\hline R9** (testemunha) & 09/04/2008 & 0,00 & 0,00 & 0,00 & 0,00 \\
\hline Acumulado & $1^{\circ}$ colheita & 0,00 & 0,00 & 0,00 & 0,00 \\
\hline & & 0,00 & 8,46 & 16,14 & 23,73 \\
\hline $\mathrm{R} 9+1 \mathrm{dia}$ & $10 / 04 / 2008$ & 0,00 & 7,72 & 15,83 & 24,30 \\
\hline $\mathrm{R} 9+2$ dias & $11 / 04 / 2008$ & 0,00 & 9,03 & 17,19 & 23,55 \\
\hline $\mathrm{R} 9+3$ dias & $12 / 04 / 2008$ & 0,00 & 8,99 & 16,10 & 22,85 \\
\hline $\mathrm{R} 9+4$ dias & $13 / 04 / 2008$ & $2,28^{*}$ & 8,03 & 15,44 & 22,41 \\
\hline $\mathrm{R} 9+5$ dias & $14 / 04 / 2008$ & & & & \\
\hline Acumulado (5 dias) & $2^{\circ}$ colheita & 2,28 & 42,23 & 80,70 & 116,83 \\
\hline & & & 9,50 & 19,00 & 28,50 \\
\hline $\mathrm{R} 9+6$ dias & $15 / 04 / 2008$ & $9,50^{*}$ & 8,90 & 17,67 & 26,53 \\
\hline $\mathrm{R} 9+7$ dias & $16 / 04 / 2008$ & $0,25^{*}$ & 7,46 & 14,65 & 22,67 \\
\hline $\mathrm{R} 9+8$ dias & $17 / 04 / 2008$ & 0,00 & 7,54 & 15,61 & 23,33 \\
\hline $\mathrm{R} 9+9$ dias & $18 / 04 / 2008$ & 0,00 & 20,00 & 35,09 & 44,47 \\
\hline $\mathrm{R} 9+10$ dias & $19 / 04 / 2008$ & $13,03^{*}$ & & & \\
\hline Acumulado (10 dias) & $3^{\circ}$ colheita & 25,06 & 95,64 & 182,72 & 262,34 \\
\hline & & & 7,98 & 16,05 & 24,60 \\
\hline $\mathrm{R9}+11$ dias & $20 / 04 / 2008$ & $25,03^{*}$ & 25,23 & 50,45 & 75,68 \\
\hline $\mathrm{R9}+12$ dias & $21 / 04 / 2008$ & 0,00 & 7,89 & 16,84 & 25,35 \\
\hline $\mathrm{R} 9+13$ dias & $22 / 04 / 2008$ & $0,50^{*}$ & 5,96 & 12,76 & 20,57 \\
\hline $\mathrm{R} 9+14$ dias & $23 / 04 / 2008$ & $0,25^{*}$ & 7,98 & 16,23 & 24,12 \\
\hline $\mathrm{R} 9+15$ dias & $24 / 04 / 2008$ & 0,00 & & & \\
\hline Acumulado (15 dias) & $4^{\circ}$ colheita & 50,80 & 150,68 & 295,05 & 432,66 \\
\hline
\end{tabular}

${ }^{*}$ Registro de precipitações. **Estádio de desenvolvimento R9 - Ponto de maturação do grão e colheita. 
ANDRADE, P. et al. Qualidade física dos grãos de soja...

Os parâmetros de avaliação foram: teor de água dos grãos, determinado em estufa de secagem por $24 \mathrm{~h} \pm 1 \mathrm{~h}$ a $105^{\circ} \mathrm{C} \pm 3^{\circ} \mathrm{C}$, de acordo com as RAS - Regras para Análises de Sementes (BRASIL, 1992) e classificação comercial de acordo com o Padrão de qualidade do Ministério de Agricultura, para grãos de soja, conforme a Instrução Normativa No 11 (IN N¹1) de 15/05/2007 (BRASIL, 2007).

O quadro de análise de variância foi calculado para as variáveis de interesse e quando esta foi significativa ( $\mathrm{F}$ calculado $>\mathrm{F}$ tabelado), o teste de Tukey a $5 \%$ de probabilidade foi utilizado para a comparação entre as médias de tratamentos. Algumas variáveis que tiveram coeficiente de variação superior a 40 foram transformadas em $(x+1)^{0,5}$. O programa utilizado para esta finalidade foi Sisvar versão 5.0 (Ferreira, 2007).

\section{RESULTADOS E DISCUSSÃO}

Os dados meteorológicos de temperatura e umidade relativa registrados durante os meses de outubro de 2007 e abril de 2008, no local do experimento, estão ilustrados nas Figuras 1 e 2. A média diária da umidade relativa do ar se manteve entre 39 e $87 \%$, para outubro de 2007 e entre 66 e $89 \%$, para o mês de abril. A temperatura média diária oscilou entre 23,3 e $31,1{ }^{\circ} \mathrm{C}$ em outubro e entre 19,8 e $29,3^{\circ} \mathrm{C}$ em abril.

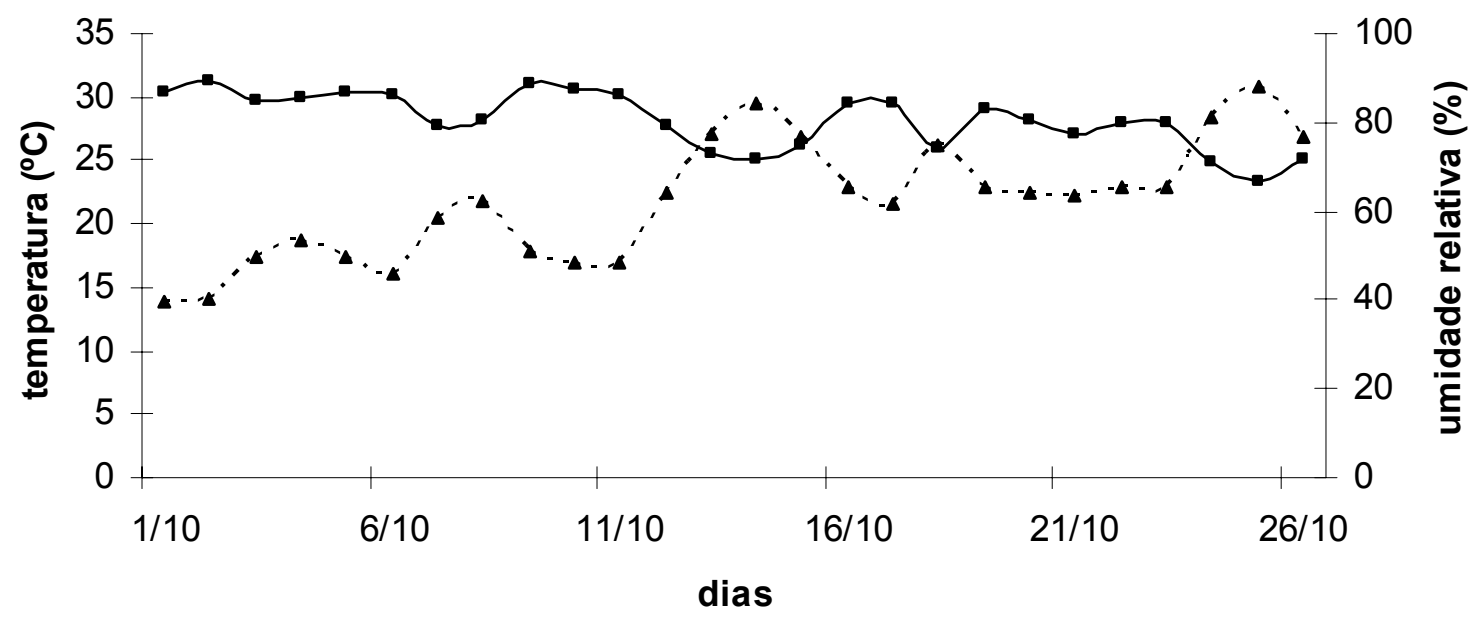

FIGURA 1 - Temperatura e umidade relativa média, diárias, do ar no período de 01/10 a 26/10/2007, no campo experimental do UNIVAG - Várzea Grande/MT.

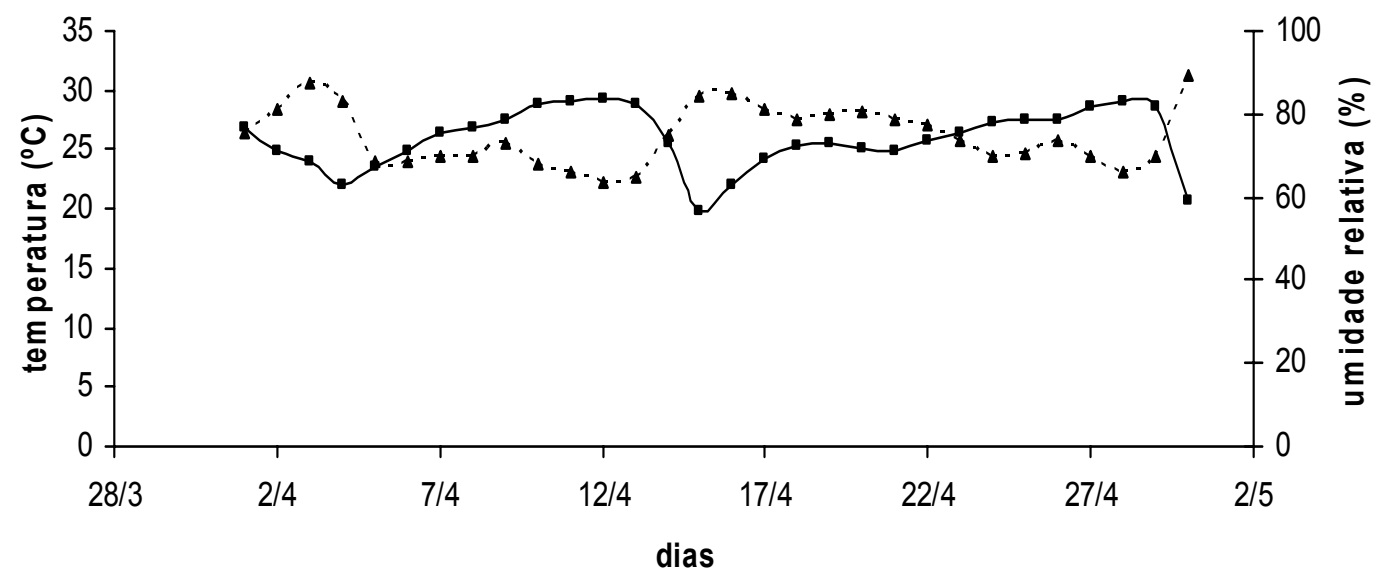

FIGURA 2 - Temperatura e umidade relativa média, diárias, do ar no período de 01/04 a 30/04/2008, no campo experimental do UNIVAG - Várzea Grande/MT. 
ANDRADE, P. et al. Qualidade física dos grãos de soja...

A chuva durante o retardamento de colheita acelerou o processo de deterioração dos grãos. Desse modo, à medida que aumentou o volume de precipitação ou volume de água recebido na simulação de chuva aumentaram também as porcentagens de grãos ardidos, mofados, avariado e fermentados. O atraso da colheita por causa da chuva causa preocupação em relação a grãos ardidos, que passam por um processo de fermentação e perdem qualidade (CONAB, 2008).

A condição atmosférica após a simulação também interferiu no processo de deterioração. Se a condição foi de elevada temperatura e umidade relativa do ar o processo foi acelerado. Segundo França Neto \& Henning (1984) a exposição de grãos de soja a ciclos alternados de umidade, antes da colheita, devido à ocorrência de chuvas freqüentes, resultará na sua deterioração. Essa deterioração será ainda mais intensa se tais condições estiverem associadas com condições de elevadas temperaturas.

\section{Teor de água}

Observa-se na Tabela 3 que até mesmo os grãos que não receberam simulação de precipitação apresentaram aumento no teor de água, entre a primeira e última colheita. Esse aumento foi devido ao retardamento de colheita, às precipitações ocorridas ao longo do experimento e ao orvalho depositado nas vagens. Para Giurizatto et al. (2003) O retardamento de colheita aumenta a porcentagem de embebição de água pelas sementes e reduz a qualidade fisiológica das mesmas.

TABELA 3 - Média da porcentagem do teor de água encontrado na soja, submetida em três tempos de simulação de chuva, do experimento instalado no UNIVAG, Várzea Grande-MT, em outubro de 2007.

\begin{tabular}{|c|c|c|c|c|}
\hline \multirow{2}{*}{$\begin{array}{c}\text { Época de } \\
\text { Colheita }\end{array}$} & \multicolumn{4}{|c|}{ Teor de água (\%) - 2007} \\
\hline & $\begin{array}{c}\text { Sem simulação de } \\
\text { chuva }\end{array}$ & $\begin{array}{c}1 \mathrm{~h} \text { de simulação } \\
\text { de chuva }\end{array}$ & $\begin{array}{c}2 \mathrm{~h} \text { de simulação } \\
\text { de chuva }\end{array}$ & $\begin{array}{c}3 \text { h de simulação de } \\
\text { chuva }\end{array}$ \\
\hline Testemunha & $8,58 \mathrm{Aa}$ & $8,55 \mathrm{Aa}$ & $8,53 \mathrm{Aa}$ & $9,10 \mathrm{Aa}$ \\
\hline 5 dias & $10,54 \mathrm{Aa}$ & $14,53 \mathrm{Bb}$ & $14,23 \mathrm{Bb}$ & $13,71 \mathrm{Bb}$ \\
\hline 10 dias & $19,82 \mathrm{Ba}$ & $26,03 \mathrm{Cbc}$ & $27,47 \mathrm{Cc}$ & $25,22 \mathrm{Cb}$ \\
\hline 15 dias & $20,10 \mathrm{Ba}$ & $25,88 \mathrm{Cbc}$ & $26,74 \mathrm{Cc}$ & $24,88 \mathrm{Cb}$ \\
\hline 22 dias & $23,36 \mathrm{Ca}$ & $33,51 \mathrm{Db}$ & $34,26 \mathrm{Db}$ & $32,67 \mathrm{Db}$ \\
\hline
\end{tabular}

DMS (\%) 1,95

Médias seguidas de mesma letra maiúsculas nas colunas e minúscula nas linhas, não diferem estatisticamente entre si pelo teste de Tukey a $5 \%$ de probabilidade. *Coeficiente de variação. **Diferença mínima significativa.

Em 2007, nas colheitas realizadas entre 10 e 15 dias, os grãos que receberam duas horas de simulação de chuva apresentaram maiores teores de água do que os de três horas. No ano de 2008 não houve diferença estatística significativa no teor de água dos grãos nos diferentes tempos de simulação de chuva. Esse comportamento, provavelmente deve-se ao fato que os grãos atingiram teor de água de equilíbrio higroscópio.

$\mathrm{Na}$ segunda colheita, para o ano de 2008, a porcentagem de teor de água dos grãos ficou superior ao recomendável para a conservação da qualidade dos mesmos que é de 14\% (Tabela 4). O atraso na colheita dos grãos, as simulações de chuva, precipitações e o orvalho favorecem a elevação dos teores de água nas amostras, contribuindo com o processo de deterioração da soja. Para Alencar et al. (2009) a combinação de teores de água e temperaturas mais elevados intensifica o processo de deterioração dos grãos. 
ANDRADE, P. et al. Qualidade física dos grãos de soja...

TABELA 4 - Média da porcentagem do teor de água encontrado na soja, submetida em três tempos de simulação de chuva, do experimento instalado no UNIVAG, Várzea Grande-MT, em abril de 2008.

\begin{tabular}{|c|c|c|c|c|}
\hline \multirow[b]{2}{*}{ Época de Colheita } & \multicolumn{4}{|c|}{ Teor de água (\%) - 2008} \\
\hline & $\begin{array}{c}\text { Sem simulação de } \\
\text { chuva }\end{array}$ & $\begin{array}{c}1 \mathrm{~h} \text { de simulação de } \\
\text { chuva }\end{array}$ & $\begin{array}{c}2 \text { h de simulação de } \\
\text { chuva }\end{array}$ & $\begin{array}{c}3 \mathrm{~h} \text { de simulação de } \\
\text { chuva }\end{array}$ \\
\hline Testemunha & $9,12 \mathrm{Aa}$ & $10,20 \mathrm{Aa}$ & $10,46 \mathrm{Aa}$ & $9,68 \mathrm{Aa}$ \\
\hline 5 dias & $18,51 \mathrm{Ba}$ & $20,99 \mathrm{Ba}$ & $21,88 \mathrm{Ba}$ & $21,45 \mathrm{Ba}$ \\
\hline 10 dias & $23,04 \mathrm{Ba}$ & $26,92 \mathrm{Ca}$ & $27,90 \mathrm{Ca}$ & $27,67 \mathrm{Ca}$ \\
\hline 15 dias & $24,00 \mathrm{Ba}$ & $27,74 \mathrm{Ca}$ & $28,87 \mathrm{Ca}$ & $28,40 \mathrm{Ca}$ \\
\hline \multicolumn{5}{|l|}{${ }^{*} \mathrm{CV}(\%) 16,30$} \\
\hline **DMS (\%) 5,72 & & & & \\
\hline
\end{tabular}

\section{Classificação Comercial \\ Grãos ardidos}

Observa-se na Tabela 5 que as porcentagens de grãos ardidos aumentaram com o retardamento de colheita. Os diferentes tempos de simulação de chuva também contribuíram para o aumento do teor de grãos ardidos, nos dois anos experimentais.

TABELA 5 - Média da porcentagem de grãos ardidos encontrados na soja, submetida em três tempos de simulação, do experimento instalado no UNIVAG, Várzea Grande/MT, em outubro de 2007.

\begin{tabular}{lrrrr}
\hline Época de Colheita & \multicolumn{4}{c}{ Grãos ardidos (\%) - 2007 } \\
\cline { 2 - 5 } & $\begin{array}{c}\text { Sem simulação de } \\
\text { chuva }\end{array}$ & $\begin{array}{c}\text { 1 h de simulação } \\
\text { de chuva }\end{array}$ & $\begin{array}{c}2 \mathrm{~h} \text { de simulação } \\
\text { de chuva }\end{array}$ & $\begin{array}{c}\text { 3 h de simulação de } \\
\text { chuva }\end{array}$ \\
\hline Testemunha & $0,05 \mathrm{Aa}$ & $0,18 \mathrm{Ab}$ & $0,17 \mathrm{Aab}$ & $0,16 \mathrm{Aab}$ \\
5 dias & $0,18 \mathrm{Aa}$ & $0,60 \mathrm{Bb}$ & $0,57 \mathrm{Bb}$ & $0,17 \mathrm{Aa}$ \\
10 dias & $1,09 \mathrm{Ba}$ & $1,75 \mathrm{Cb}$ & $2,58 \mathrm{Cc}$ & $1,64 \mathrm{Bb}$ \\
15 dias & $1,14 \mathrm{Ca}$ & $1,86 \mathrm{Cb}$ & $2,76 \mathrm{Dd}$ & $2,27 \mathrm{Cc}$ \\
22 dias & $2,40 \mathrm{Da}$ & $3,32 \mathrm{Db}$ & $4,18 \mathrm{Ed}$ & $3,80 \mathrm{Dc}$ \\
\hline
\end{tabular}

${ }^{*} \mathrm{CV}(\%) 4,96$

${ }^{\star *}$ DMS (\%) 1,28

Médias seguidas de mesma letra maiúsculas nas colunas e minúscula nas linhas, não diferem estatisticamente entre si pelo teste de Tukey a $5 \%$ de probabilidade. *Coeficiente de variação. ${ }^{*}$ Diferença mínima significativa.

Em 2007, a maior porcentagem de grãos ardidos foi obtida aos 22 dias com duas horas de simulação de chuva. Entretanto, em 2008 a maior porcentagem foi adquirida aos 15 dias, no tempo de simulação de três horas. Nesse mesmo ano, os grãos colhidos, nas duas primeiras colheitas, não apresentaram diferença na porcentagem de grãos ardidos com os diferentes tempos de simulação (Tabela 6). Os grãos colhidos no ano de 2007 até a segunda colheita (cinco dias após R9) não ultrapassaram 0 limite de ardidos para enquadramento como Tipo 1 (Grupo I), em nenhum dos tempos de simulação. Com 10 dias de retardamento de colheita, somente os grãos que receberam duas horas de simulação se enquadraram como Padrão Básico (Grupo II), os demais tratamentos ficaram como Tipo 2 (Grupo I). Ao final do experimento, 22 dias após a primeira colheita, os grãos se enquadraram como Padrão Básico, exceto os que receberam duas horas de simulação, enquadrados como Fora de Tipo. 
ANDRADE, P. et al. Qualidade física dos grãos de soja...

TABELA 6 - Média da porcentagem de grãos ardidos encontrados na soja, submetida em três tempos de simulação de chuva, do experimento instalado no UNIVAG, Várzea Grande-MT, em abril de 2008

\begin{tabular}{lcccc}
\hline \multirow{2}{*}{ Época de Colheita } & \multicolumn{4}{c}{ Grãos ardidos $(\%)-2008$} \\
\cline { 2 - 5 } & $\begin{array}{c}\text { Sem simulação de } \\
\text { chuva }\end{array}$ & $\begin{array}{c}\text { 1 h de simulação } \\
\text { de chuva }\end{array}$ & $\begin{array}{c}2 \mathrm{~h} \text { de simulação } \\
\text { de chuva }\end{array}$ & $\begin{array}{c}3 \text { h de simulação de } \\
\text { chuva }\end{array}$ \\
\hline Testemunha & $0,16(1,07) \mathrm{A} \mathrm{a}$ & $0,10(1,04) \mathrm{Aa}$ & $0,26(1,12) \mathrm{Aa}$ & $0,26(1,11) \mathrm{Aa}$ \\
5 dias & $0,33(1,15) \mathrm{Aa}$ & $0,35(1,16) \mathrm{Aba}$ & $0,48(1,21) \mathrm{Aa}$ & $0,64(1,27) \mathrm{Aa}$ \\
10 dias & $0,54(1,23) \mathrm{Aa}$ & $1,01(1,41) \mathrm{ABab}$ & $1,89(1,65) \mathrm{Bb}$ & $1,96(1,68) \mathrm{Bb}$ \\
15 dias & $0,72(1,31) \mathrm{Aa}$ & $1,46(1,51) \mathrm{Bab}$ & $2,21(1,76) \mathrm{Bbc}$ & $4,02(2,17) \mathrm{Cc}$ \\
\hline
\end{tabular}

Cv (\%) 18,00

DMS (\%) 0,41

Médias seguidas de mesma letra maiúsculas nas colunas e minúscula nas linhas, não diferem estatisticamente entre si pelo teste de Tukey a $5 \%$ de probabilidade. Dados entre parênteses foram transformados em $(x+1)^{0,5}$. As comparações das médias foram feitas com base nos dados transformados. ${ }^{*}$ Coeficiente de variação. ${ }^{*}$ Diferença mínima significativa.

Para os grãos colhidos na safra 2007/08, em relação à porcentagem de grãos ardidos, até a terceira colheita, todos os tratamentos, exceto a testemunha, foram enquadrados no Grupo I, sendo que a, primeira e a segunda colheita, foram classificadas como Tipo 1 e a terceira como Tipo 2. Com 15 dias de atraso de colheita a testemunha ainda foi classificada como Tipo 1, a soja que recebeu uma hora de simulação foi enquadrada como Tipo 2, a de duas horas como Padrão Básico e a da três horas como Fora de Tipo, por exceder em apenas $0,2 \%$ o limite tolerável de $4 \%$. A simulação de chuva contribuiu para o aumento de teor de água dos grãos, favorecendo o processo de fermentação e, posteriormente, a formação de grãos ardidos.

\section{Grãos mofados}

Grãos mofados foi o defeito de maior ocorrência nos dois anos e não houve diferença estatística na porcentagem entre as duas primeiras colheitas. Quanto maior foi o tempo de simulação de chuva e o retardamento de colheita, maior a porcentagem de grãos mofados nas amostras (Tabelas 7 e 8). Os dados estão de acordo com Santos et al. (2005), que avaliando a qualidade fisiológica e sanitária de soja colhidas em diferentes épocas, observaram que a ocorrência de fungos foi menor em grãos colhidos em R9, com tendência a maiores porcentagens em grãos colhidos aos 30 dias após esse estádio.

TABELA 7 - Média da porcentagem de grãos mofados encontrados na soja, submetida em três tempos de simulação de chuva, do experimento instalado no UNIVAG, Várzea Grande-MT, em outubro de 2007.

\begin{tabular}{lcccc}
\hline & \multicolumn{4}{c}{ Grãos mofados (\%) - 2007 } \\
\cline { 2 - 5 } Época de Colheita & $\begin{array}{c}\text { Sem simulação de } \\
\text { chuva }\end{array}$ & $\begin{array}{c}1 \text { h de simulação } \\
\text { de chuva }\end{array}$ & $\begin{array}{c}2 \text { h de simulação } \\
\text { de chuva }\end{array}$ & $\begin{array}{c}3 \mathrm{~h} \text { de simulação de } \\
\text { chuva }\end{array}$ \\
\hline Testemunha & $0,12 \mathrm{Aa}$ & $0,10 \mathrm{Aa}$ & $0,11 \mathrm{Aa}$ & $0,13 \mathrm{Aa}$ \\
5 dias & $0,12 \mathrm{Aa}$ & $0,36 \mathrm{Aa}$ & $0,27 \mathrm{Aa}$ & $32,02 \mathrm{Bc}$ \\
10 dias & $5,22 \mathrm{Ba}$ & $29,93 \mathrm{Bb}$ & $38,73 \mathrm{Bc}$ & $40,08 \mathrm{Bc}$ \\
15 dias & $5,75 \mathrm{Ba}$ & $31,36 \mathrm{Bb}$ & $40,19 \mathrm{Bc}$ & $50,09 \mathrm{Cc}$ \\
22 dias & $8,28 \mathrm{Ca}$ & $41,40 \mathrm{Cb}$ & $49,71 \mathrm{Cc}$ & 52
\end{tabular}

CV (\%) 6,14

DMS (\%) 2,06

Médias seguidas de mesma letra maiúsculas nas colunas e minúscula nas linhas, não diferem estatisticamente entre si pelo teste de Tukey a $5 \%$ de probabilidade. ${ }^{\star}$ Coeficiente de variação. **Diferença mínima significativa. 
ANDRADE, P. et al. Qualidade física dos grãos de soja...

TABELA 8 - Média da porcentagem de grãos mofados encontrados na soja, submetida em três tempos de simulação de chuva, do experimento instalado no UNIVAG, Várzea Grande-MT, em abril de 2008.

\begin{tabular}{|c|c|c|c|c|}
\hline \multirow{2}{*}{$\begin{array}{l}\text { Época de } \\
\text { Colheita }\end{array}$} & \multicolumn{4}{|c|}{ Grãos mofados (\%) - 2008} \\
\hline & $\begin{array}{c}\text { Sem simulação de } \\
\text { chuva }\end{array}$ & $\begin{array}{c}1 \mathrm{~h} \text { de simulação } \\
\text { de chuva }\end{array}$ & $\begin{array}{c}2 \mathrm{~h} \text { de simulação } \\
\text { de chuva }\end{array}$ & $\begin{array}{c}3 \text { h de simulação de } \\
\text { chuva }\end{array}$ \\
\hline Testemunha & $0,64 \mathrm{Aa}$ & $0,65 \mathrm{Aa}$ & $0,23 \mathrm{Aa}$ & $0,84 \mathrm{Aa}$ \\
\hline 5 dias & $2,71 \mathrm{Aa}$ & $3,22 \mathrm{Aa}$ & $2,75 \mathrm{Aa}$ & 3,68 Aa \\
\hline 10 dias & $6,45 \mathrm{ABa}$ & $19,06 \mathrm{Bb}$ & $21,05 \mathrm{Bb}$ & $24,91 \mathrm{Bb}$ \\
\hline 15 dias & $10,92 \mathrm{Ba}$ & $45,99 \mathrm{Cb}$ & $50,26 \mathrm{Cbc}$ & $55,67 \mathrm{Cc}$ \\
\hline
\end{tabular}

Cv (\%) 29,80

DMS 7,74

Médias seguidas de mesma letra maiúsculas nas colunas e minúscula nas linhas, não diferem estatisticamente entre si pelo teste de Tukey a $5 \%$ de probabilidade. ${ }^{*}$ Coeficiente de variação. ${ }^{*}$ Diferença mínima significativa.

O tempo de simulação de $1 \mathrm{~h}$ apresentou expressivo aumento na porcentagem de grãos mofados (>29\% em 2007 e $>19 \%$ em 2008 ), a partir dos 10 dias de retardamento de colheita. O elevado teor de água dos grãos ( $>14 \%$ ), e as condições de umidade relativa (UR $>60 \%$ ) e temperatura do ar $\left(>25^{\circ} \mathrm{C}\right)$ contribuíram para a proliferação de fungos. Oscilações freqüentes de temperatura, associadas às chuvas durante o período de maturidade da soja, têm sido detectadas como fatores que contribuem de forma relevante para a redução das qualidades fisiológica e sanitária das sementes (Costa et al., 1994). Os mesmos autores constataram que baixas temperaturas favorecem a qualidade da semente e que condições quentes e úmidas, com excesso de precipitação, podem afetar de forma irreversível a qualidade da soja produzida. Lacerda (2007) estudando os fatores que afetam a maturação e qualidade fisiológica das sementes de soja encontrou alta incidência de fungos do gênero Phomopsis em conseqüência de elevados índices de precipitação pluviométrica durante a maturação da soja.

Em 2007, a porcentagem de grãos mofados permaneceu dentro do limite de tolerância para o Tipo 1 até a segunda colheita, para todos os tratamentos. A partir da terceira colheita somente a testemunha ficou dentro do limite para o enquadramento como Padrão Básico, porém na colheita seguinte já foi classificada como Fora de Tipo, com $8,28 \%$ de grãos mofados.
Em abril de 2008, até a segunda colheita, para todos os tratamentos, as amostras de soja enquadraram-se como Padrão Básico e com 10 dias de colheita todos os tratamentos foram classificados como Fora de Tipo, e os grãos que receberam simulação de chuva foram desclassificados para o consumo humano, podendo ser destinado a outros usos. Na última colheita a testemunha continua com a mesma classificação da anterior, porém, a porcentagem de grãos mofados dos demais tratamentos foi superior a $40 \%$.

De acordo com a IN N ${ }^{\circ} 11$, o grão mofado é considerado um defeito grave, e a soja que apresentar percentual de defeitos graves superior a $40 \%$ é desclassificada e proibida sua comercialização para a alimentação humana e outros usos.

\section{Grãos picados}

A partir da terceira colheita, em 10 dias, as maiores porcentagens de grãos picados foram encontradas nas amostras que não receberam simulação de chuva (Tabela 9). O retardamento de colheita contribuiu para o aumento de grãos picados colhidos nos anos de 2007 e 2008, possivelmente devido ao maior tempo de exposição dos grãos aos insetos. Em 2007, com exceção das amostras que não receberam simulação de chuva, as duas primeiras colheitas não diferiram significativamente entre si, entretanto, diferiram das duas últimas (Tabela 10). 
ANDRADE, P. et al. Qualidade física dos grãos de soja...

TABELA 9 - Média da porcentagem de grãos picados encontrados na soja, submetida em três tempos de simulação de chuva, do experimento instalado no UNIVAG, Várzea Grande-MT, em outubro de 2007.

\begin{tabular}{llccc}
\hline \multirow{2}{*}{ Época de Colheita } & \multicolumn{4}{c}{ Grãos picados (\%) - 2007 } \\
\cline { 2 - 5 } & $\begin{array}{c}\text { Sem simulação de } \\
\text { chuva }\end{array}$ & $\begin{array}{c}1 \mathrm{~h} \text { de simulação } \\
\text { de chuva }\end{array}$ & $\begin{array}{c}2 \mathrm{~h} \text { de simulação } \\
\text { de chuva }\end{array}$ & $\begin{array}{c}3 \mathrm{~h} \text { de simulação de } \\
\text { chuva }\end{array}$ \\
\hline Testemunha & $3,01 \mathrm{Aa}$ & $2,93 \mathrm{Aa}$ & $2,66 \mathrm{Aa}$ & $3,06 \mathrm{Aa}$ \\
5 dias & $7,08 \mathrm{Bb}$ & $5,72 \mathrm{Ba}$ & $6,98 \mathrm{Bb}$ & $7,30 \mathrm{Bb}$ \\
& & & & $7,75 \mathrm{Bb}$ \\
10 dias & $10,91 \mathrm{Cd}$ & $6,16 \mathrm{Ba}$ & $8,81 \mathrm{Cc}$ & $8,56 \mathrm{Cb}$ \\
15 dias & $13,98 \mathrm{Dd}$ & $7,75 \mathrm{Ca}$ & $10,46 \mathrm{Dc}$ & $10,45 \mathrm{Db}$ \\
\hline
\end{tabular}

cv $(\%) 4,17$

DMS (\%) 0,56

Médias seguidas de mesma letra maiúsculas nas colunas e minúscula nas linhas, não diferem estatisticamente entre si pelo teste de Tukey a $5 \%$ de probabilidade. *Coeficiente de variação. **Diferença mínima significativa.

TABELA 10 - Média da porcentagem de grãos picados encontrados na soja, submetida em três tempos de simulação de chuva, do experimento instalado no UNIVAG, Várzea Grande/MT, em abril de 2008.

\begin{tabular}{lcccc}
\hline \multirow{2}{*}{ Época de Colheita } & \multicolumn{4}{c}{ Grãos picados (\%) - 2008 } \\
\cline { 2 - 5 } & $\begin{array}{c}\text { Sem simulação de } \\
\text { chuva }\end{array}$ & $\begin{array}{c}\text { 1 h de simulação de } \\
\text { chuva }\end{array}$ & $\begin{array}{c}\text { 2 h de simulação de } \\
\text { chuva }\end{array}$ & $\begin{array}{c}\text { 3 h de simulação de } \\
\text { chuva }\end{array}$ \\
\hline Testemunha & $1,58(1,58) \mathrm{Aa}$ & $1,12(1,44) \mathrm{Aa}$ & $1,37(1,52) \mathrm{Aa}$ & $1,12(1,44) \mathrm{Aa}$ \\
5 dias & $2,88(1,96) \mathrm{ABa}$ & $2,91(1,95) \mathrm{ABa}$ & $3,93(2,09) \mathrm{ABa}$ & $2,18(1,77) \mathrm{ABa}$ \\
10 dias & $3,97(2,22) \mathrm{ABa}$ & $4,35(2,30) \mathrm{Ba}$ & $4,88(2,32) \mathrm{Ba}$ & $3,51(2,11) \mathrm{Ba}$ \\
15 dias & $5,36(2,51) \mathrm{Ba}$ & $5,47(2,53) \mathrm{Ba}$ & $6,03(2,57) \mathrm{Ba}$ & $4,25(2,28) \mathrm{Ba}$ \\
\hline
\end{tabular}

CV (\%) 19,45

DMS (\%) 0,66

Médias seguidas de mesma letra maiúsculas nas colunas e minúscula nas linhas, não diferem estatisticamente entre si pelo teste de Tukey a $5 \%$ de probabilidade. Dados entre parênteses foram transformados em $(x+1)^{0,5}$. As comparações das médias foram feitas com base nos dados transformados. *Coeficiente de variação. **Diferença mínima significativa.

Ao avaliarem danos causados por percevejos em sementes de soja, Sarmento et al. (2002) concluíram que a falta de controle pode acarretar prejuízos quantitativos e qualitativos e que a infestação de dois percevejos por metro linear, durante todo o ciclo reprodutivo da cultura, pode causar perda total da produção e inviabilizar a industrialização do grão.

\section{Total de grãos avariados}

Os valores da porcentagem do total de grãos avariados, colhidos em diferentes épocas, diferiram significativamente entre si em todos os tempos de simulação de chuva. Com 10 dias de retardamento de colheita, as amostras que receberam duas e três horas de simulação de chuva apresentaram-se com mais de $50 \%$ das amostras com grãos avariados.

No tempo de simulação de duas horas, na colheita de 22 dias, menos de $10 \%$ da amostra era composta por grãos sadios. A testemunha apresentou mais de $50 \%$ de grãos avariados na última colheita, embora não tenha recebido simulação de chuva. Nota-se que os grãos que receberam duas horas de simulação de chuva tiveram maior porcentagem de avariados em relação aos outros tempos (Tabela 11). Entretanto, o teor de água desses grãos também foi maior, o que justifica a maior ocorrência dos defeitos. 
ANDRADE, P. et al. Qualidade física dos grãos de soja...

TABELA 11 - Média da porcentagem de grãos avariados encontrados na soja, submetida em três tempos de simulação de chuva, do experimento instalado no UNIVAG, Várzea Grande-MT, em outubro de 2007.

\begin{tabular}{lrrrr}
\hline \multirow{2}{*}{ Época de Colheita } & \multicolumn{4}{c}{ Grãos avariados (\%) - 2007 } \\
\cline { 2 - 5 } & $\begin{array}{c}\text { Sem simulação de } \\
\text { chuva }\end{array}$ & $\begin{array}{c}1 \mathrm{~h} \text { de simulação de } \\
\text { chuva }\end{array}$ & $\begin{array}{c}2 \mathrm{~h} \text { de simulação de } \\
\text { chuva }\end{array}$ & $\begin{array}{c}\text { 3 h de simulação de } \\
\text { chuva }\end{array}$ \\
\hline Testemunha & $5,94 \mathrm{Aa}$ & $8,20 \mathrm{Aa}$ & $7,45 \mathrm{Aa}$ & $7,81 \mathrm{Aa}$ \\
5 dias & $15,21 \mathrm{Bab}$ & $14,31 \mathrm{Ba}$ & $19,16 \mathrm{Bc}$ & $17,05 \mathrm{Bbc}$ \\
10 dias & $32,39 \mathrm{Ca}$ & $47,71 \mathrm{Cb}$ & $64,80 \mathrm{Cd}$ & $57,29 \mathrm{Cc}$ \\
15 dias & $44,45 \mathrm{Da}$ & $55,61 \mathrm{Db}$ & $74,74 \mathrm{Dd}$ & $64,82 \mathrm{Dc}$ \\
22 dias & $59,06 \mathrm{Ea}$ & $73,56 \mathrm{~Eb}$ & $92,12 \mathrm{Ed}$ & $82,81 \mathrm{Ec}$ \\
\hline
\end{tabular}

cv (\%) 3,37

DMS (\%) 2,36

Médias seguidas de mesma letra maiúsculas nas colunas e minúscula nas linhas, não diferem estatisticamente entre si pelo teste de Tukey a $5 \%$ de probabilidade. *Coeficiente de variação. **Diferença mínima significativa.

Mesmo não recebendo água, através da simulação de precipitação, os grãos colhidos na testemunha, em outubro de 2007, obtiveram porcentagem de grãos avariados superior a $50 \%$, com 15 dias de retardamento de colheita, provavelmente, efeito das chuvas ocorridas no período do experimento, acumulado de $127,95 \mathrm{~mm}$ ao final dos 22 dias.
Com cinco dias de retardamento de colheita, em 2007, o total de avariados excedeu o limite máximo de tolerância previsto na IN $N^{\circ} 11$, que é de $8 \%$, sendo a porcentagem de grãos fermentados o defeito que mais contribuiu para tal excesso, independente dos tratamentos (Tabela 12).

TABELA 12 - Média da porcentagem do total de grãos avariados encontrados na soja, submetida em três tempos de simulação de chuva, do experimento instalado no UNIVAG, Várzea Grande-MT, em abril de 2008.

\begin{tabular}{lllcl}
\hline \multirow{2}{*}{ Época de Colheita } & \multicolumn{4}{c}{ Grãos avariados (\%) - 2008 } \\
\cline { 2 - 5 } & $\begin{array}{c}\text { Sem simulação de } \\
\text { chuva }\end{array}$ & $\begin{array}{c}1 \mathrm{~h} \text { de simulação } \\
\text { de chuva }\end{array}$ & $\begin{array}{c}\text { 2 h de simulação } \\
\text { de chuva }\end{array}$ & $\begin{array}{c}3 \mathrm{~h} \text { de simulação } \\
\text { de chuva }\end{array}$ \\
\hline Testemunha & $2,80 \mathrm{Aa}$ & $2,29 \mathrm{Aa}$ & $2,02 \mathrm{Aa}$ & $2,63 \mathrm{Aa}$ \\
5 dias & $7,11 \mathrm{Aa}$ & $8,07 \mathrm{Aa}$ & $7,98 \mathrm{Aa}$ & $7,85 \mathrm{Aa}$ \\
10 dias & $12,64 \mathrm{Aba}$ & $27,63 \mathrm{Bb}$ & $29,86 \mathrm{Bb}$ & $33,34 \mathrm{Bb}$ \\
15 dias & $19,15 \mathrm{Ba}$ & $57,56 \mathrm{Cb}$ & $62,11 \mathrm{Cbc}$ & $68,75 \mathrm{Cc}$ \\
\hline
\end{tabular}

CV (\%) 28,40

\section{DMS (\%) 10,41}

Médias seguidas de mesma letra maiúsculas nas colunas e minúscula nas linhas, não diferem estatisticamente entre si pelo teste de Tukey a $5 \%$ de probabilidade. *Coeficiente de variação. ${ }^{* \star D}$ Diferença mínima significativa. 
ANDRADE, P. et al. Qualidade física dos grãos de soja...

Desde a primeira colheita, em 2007, a porcentagem do total de grãos avariados não se enquadrou no Grupo I. Na segunda colheita, toda a soja colhida, independente do tempo de simulação de chuva, foi classificada como Fora de Tipo. A soja que recebeu $2 \mathrm{~h}$ de simulação de chuva ficou próxima de atingir $100 \%$ de grãos avariados.

Em abril de 2008, com cinco dias de retardamento de colheita, somente os grãos que receberam uma hora de simulação de chuva não ultrapassaram o limite máximo de tolerância previsto na $\mathrm{IN} \mathrm{N}^{\circ} 11$, ficando próximo a $8 \%$, entretanto, não diferiram dos demais tratamentos e, a partir de 10 dias, todos ultrapassaram este valor. As porcentagens de grãos avariados, para as amostras que receberam simulação de chuva, alcançaram $50 \%$ somente na última colheita, aos 15 dias de retardamento (Tabela 12). Não houve diferença estatística a partir da segunda colheita, com relação à porcentagem do total de grãos avariados. Nessas colheitas também não houve diferença entre os diferentes tempos de simulação, com exceção das amostras que não receberam simulação, as outras apresentaram diferença estatística entre as duas últimas colheitas.

Com o atraso da época de colheita, após a maturidade fisiológica dos grãos, para ambos os experimentos, iniciou-se um processo de deterioração dos grãos, que foi agravado pelo processo de simulação de chuva. Para França Neto et al. (1984) as maiores perdas ocorrem quando as sementes secas de soja são expostas à água da chuva e orvalho. Durante as primeiras exposições, o tegumento com sucessivas hidratações começa a apresentar distúrbios químicos e fisiológicos. Os estados iniciais de deterioração são geralmente superficiais, não provocando perdas imediatas.

França Neto et al. (1994) argumentam que, para as condições tropicais brasileiras onde ocorrem altas temperaturas e excesso de chuvas no estádio de maturação da soja, a alternativa mais viável para produção de sementes de alta qualidade seria a escolha de regiões com altitude superior a $800 \mathrm{~m}$, onde predomine condições de temperatura amena associada a baixos índices de precipitação no período de maturação da colheita.

\section{CONCLUSÕES}

A qualidade comercial diminui com a associação entre chuva e retardamento de colheita devido à deterioração de grãos, na cultivar TMG115RR, ocorrendo o aumento da quantidade de grãos danificados.

\section{REFERÊNCIAS}

1. ALENCAR, E. R. et al. Qualidade dos grãos de soja armazenados em diferentes condições. Engenharia Agrícola e Ambiental, v. 13, n. 5, p. 606-613, 2009.

2. AYOAD, J. O. Introdução à climatologia para os trópicos. 10 ed.. Rio de Janeiro: Bertrand Brasil, 2007. 332 p.

3. BRACCINI, A. L. et al. Qualidade fisiológica e sanitária das sementes de quinze cultivares de soja (Glycine $\max (\mathrm{L}$.) Merrill) colhidas na época normal e após o retardamento da colheita. Acta Scientiarum Agronomy, v. 25, n. 2, p. 449457, 2003.

4. BRASIL. Ministério da Agricultura e Reforma Agrária. Regras para Análise de sementes. Brasília: SNAD/CLAV, 1992. $365 \mathrm{p}$.

5. BRASIL. Ministério de Agricultura. Pecuária e Abastecimento. Instrução Normativa №11. Institui o Padrão Oficial de Classificação de Soja. Diário Oficial da União. Brasília. n 93. p 13 -15. 16 de maio de 2007. Seção 1.

6. COMPANHIA NACONAL DE ABASTECIMENTO (CONAB). Acompanhamento da safra brasileira: grãos, décimo segundo levantamento/ setembro/2008. Disponivel em: <http://www.conab.gov.br/conabweb/dowload/safra/ estudo safra.pdf>. Acesso em: 01 nov. 2008.

7. $\operatorname{COSTA}$, N. P. et al. Zoneamento ecológico do Estado do Paraná para produção de sementes de cultivares precoces de soja. Revista Brasileira de Sementes, v. 16, n. 1, p. 12-19, 1994.

8. COSTA, N. P. et al. Qualidade fisiológica, física e sanitária de sementes de soja produzidas no Brasil. Revista Brasileira de Sementes, v. 25, n. 1, p. 128-132, 2003.

9. FERREIRA, D. F. Sisvar Versão 5.0. Lavras: UFLA, 2007

10. FRANCAA NETO, J. B.; HENNING, A. A. Qualidade fisiológica e sanitária da semente de soja. Londrina: EMBRAPA CNPSo, 1984. 39 p. (Circular Técnica, 9).

11. FRANÇA NETO, J. B; HENNING, A.A; KRZYZANOWSKI, F.C. Seed production and technology for the tropics. In: EMBRAPA. Centro Nacional de Pesquisa de Soja. Tropicalsoybean: improvement and production. Roma: FAO, 1994. p. 217-240.

12. GIURIZATTO, M. I. K. et al. Efeito da época de colheita e da espessura do tegumento sobre a viabilidade e o vigor de sementes de soja. Ciência e Agrotecnologia, v. 27, n. 4, p.771-779, 2003.

13. LACERDA, A. L. S. Fatores que afetam a maturação e qualidade fisiológica das sementes de soja (G/ycine max (L.) Merrill). 2007. Artigo em Hypertexto. Disponível em: <http://www.infobibos.com/Artigos/2007_3/maturacao/ index.htm>. Acesso em: 02 dez. 2008

14. PANIZZI, R. R. et al. Efeito de danos de Piezodorus guildinni (Westwood, 1837) no rendimento e qualidade da soja. In SEMINÁRIO NACIONAL DE PESQUISA DE SOJA, 1., Londrina, 1978. Anais... Londrina: EMBRAPA-CNPSo, 1979. v. 2 p . 59-78.

15. SANTOS, M. R. et al. Qualidade fisiológica e sanitária de sementes de soja colhidas em diferentes épocas e seu potencial de armazenamento. Revista Brasileira de Armazenamento, v. 30, n. 1, p. 52-64, 2005.

16. SARMENTO, R. A. et al. Danos causados por Piezodorus guildinii (Heteroptera, Pentatomidae) em sementes de soja em Gurupu, Tocantins. Revista Ceres, v. 49, n. 286, p. 571, 2002.

17. SILVA, C. M.; MESQUITA, A. N.; PEREIRA, L. A. G. Efeito da época de colheita na qualidade da semente de soja. Revista Brasileira de Sementes, v. 1, n. 2, p. 41-48, 1979. 